\title{
FORMAS DE RESISTÊNCIA DOS TRABALHADORES PETROLEIROS
}

\author{
OIL WORKERS' FORMS OF RESISTANCE
}

\author{
Fernando Gabriel Lopes Cavalcante ${ }^{1}$ \\ Carla Appolinário de Castro ${ }^{2}$
}

\section{RESUMO}

A atual pesquisa tem como objetivo geral de análise observar as formas de reivindicação da categoria petroleira. Trataremos, dessa forma, de dois aspectos: o primeiro relacionado à pauta de reivindicação da categoria petroleira, o segundo ao modo como esses trabalhadores realizam suas reivindicações. Nossa metodologia é do tipo empírica e tendo como corpo de observação entrevistas realizadas com petroleiros e petroleiras. Utilizamos como recorte teórico as elaborações produzidas por György Lukács, de modo a compreender que a fundamentabilidade do trabalho deriva em aspectos complexos da sociabilidade humana. Além disso, utilizamos como base bibliográfica autores que tratam a respeito da categoria petroleira em específico, como por exemplo, Caldeira Brant e Francisco de Oliveira. No que se refere à discussão a respeito das resistências e às formas de organização da classe trabalhadora utilizamos como aporte teórico as obras de Thompson e Scott. Justifica-se a presente pesquisa, pois é de grande importância analisar como a categoria de trabalhadores petroleiros organizam-se politicamente e quais os reflexos dessa organização na conquista de direitos. Partimos da hipótese conclusiva inicial de que o conteúdo da reinvindicação petroleira tem como base a distribuição de valor no processo de exploração do trabalho.

Palavras-chaves: Petroleiros; Reivindicações; Trabalho.

\begin{abstract}
This research's general goal is to analyze oil workers' agendas of resistance. We observed two aspects in this study: the oil workforce political platform and the ways they advocate. Our empirical methodology included interviews with oil workers as research tools. We used György Lukács as a theoretical outline to foster an understanding of complex aspects of human sociability as underpinning elements of work. In addition, our bibliography included authors who deal with the specific struggles of oil workers, such as Caldeira Brant and Francisco de Oliveira. Regarding the discussion about the resistance and organizing methods of the working class, we used Thompson and Scott as theoretical support. This research is of great importance as it analyzes how oil workers organize themselves politically and its consequences on workers' rights victories. We start from the initial conclusive hypothesis that the oil workers' advocacy platform is based on the value distribution in labor exploitation.
\end{abstract}

Keywords: Oil workers; Rights; Resistance.

\footnotetext{
${ }^{1}$ Mestre em Sociologia e Direito pela Universidade Federal Fluminense. Especialista em Direito Previdenciário pela Universidade Católica do Salvador. Graduado em Direito pela Universidade Estadual de Feira de Santana.

${ }^{2}$ Atualmente é Professora Adjunta do departamento de direito privado da Faculdade de Direito e do Programa de Pós-Graduação de Sociologia e Direito da UFF/RJ. Doutora em Ciências Jurídicas e Sociais - UFF/RJ. e-mail: carla_appollinario@id.uff.br
} 
Revista

Debates Insubmissos

\section{INTRODUÇÃO}

Ao desenvolver a pesquisa que dá origem ao texto "Quando novos personagens entram em cena", Eder Sader buscava captar uma prática social específica. Essa prática social expressava-se através de novos sujeitos coletivos que despontavam na realidade social brasileira. Desse modo, o final da década de 1970 e o começo da década de 1980 rearticularam o cenário político nacional com grandes greves massivas e o surgimento de novos movimentos sociais. No entanto, aquilo que se enxergava na arena macrossocial só podia existir desde que atrelado a novas práticas sociais cotidianas que alargavam a conceituação do que é ou não política. Esse é o caminho apontado por Sader da seguinte maneira:

Ao observarmos as práticas desses movimentos, nós nos damos conta de que eles efetuaram uma espécie de alargamento do espaço da política. Rechaçando a política tradicionalmente instituída e politizando questão do cotidiano dos lugares de trabalho e de moradia, eles 'inventaram' novar formas de política. Mas a história dos movimentos sociais não é apenas a sua história interna. Os trabalhadores são o resultado não somente de suas próprias ações, mas também da sua interação com outros agentes. A 'política reinventada' dos movimentos teve de se enfrentar com a 'velha política' ainda dominante no sistema estatal. Como os movimentos sociais dos trabalhadores incidem sobre o sistema de poder estabelecido? Como se determinam reciprocamente os diversos agentes políticos no cenário público transformado? Essas questões se colocaram de forma flagrante já na década de 80. Mas creio que a compreensão das potencialidades dos movimentos sociais exige que nos voltemos para as modalidades de seus processos de constituição, na década anterior. Procurei contribuir para isso. (SADER, 1988, p. 20).

O presente trabalho sobre o qual nos debruçamos busca analisar uma prática social reproduzida por uma parcela específica da classe trabalhadora. Aqui analisaremos "como a categoria petroleira reivindica seus direitos". Apesar da especificidade, no entanto, não é de menor importância o local histórico ocupado pelos petroleiros no cenário nacional brasileiro desde pelo menos a grande greve de 1983.

Assim, o intuito é então realizar a discussão em dois planos, o primeiro tópico de desenvolvimento da pesquisa que será analisado "qual é a pauta da categoria petroleira?", ou seja, “o que eles defendem?”, “o que querem?”. O segundo e último tópico de desenvolvimento da pesquisa tratará especificamente de "como os petroleiros reivindicam seus direitos?", de forma que abordaremos o movimento em si da reivindicação. Assim como o ato de trabalho petroleiro pressupõe um movimento, desde furar o poço até distribuir a gasolina, 


\section{kevitte

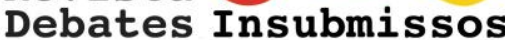

compreendemos que a reivindicação por direitos dos petroleiros expressa-se em atos, desde participar de uma assembleia até trancar a porta da refinaria.

Para o desenvolvimento da presente pesquisa utilizamos, metodologicamente, entrevistas semiestruturadas, e obras que abordam o trabalho petroleiro. Entrevistamos ao todo 11 petroleiros, um ex-presidente da Petrobras e um assessor sindical da Federação Única dos Petroleiros. Alguns dos petroleiros foram entrevistados duas vezes, como é o caso de Wanda, Machado e Sérgio Abade. De forma que ao todo foram feitas 16 entrevistas. As entrevistas ocorreram por telefone, exceto uma que foi realizada por escrito em razão de que o entrevistado alegou que "falar ao celular faz mal pra saúde!". Dos petroleiros entrevistados, um deles é do Rio de Janeiro, quatro deles são de São Paulo e 6 são da Bahia. Duas são petroleiras mulheres, o restante são homens. Um deles tem aproximação política com a Federação Nacional dos Petroleiros, os outros ou tem aproximação política com a Federação Única dos Petroleiros ou apresentam independência política em relação às federações. Dois dos petroleiros entrevistados são negros, o restante da raça branca. Foram entrevistados desde trabalhadores que entraram na Petrobras na década de 80 e 90, estando hoje aposentados, até trabalhadores que entraram depois da década de 2000, estando na ativa até hoje.

A proposta do presente escrito trabalha com a perspectiva da busca pelo real. A nossa noção de realidade concreta parte primeiramente da percepção de que nada é em si mesmo, mas que os objetos sociais são ao mesmo tempo aquilo que são e o seu contrário, são afirmação de algo e negação de algo. Nesse sentido Kosiq assim expõe:

O mundo da pseudoconcreticidade é um claro-escuro de verdade e engano. O seu elemento próprio é o duplo sentido. $\mathrm{O}$ fenômeno indica a essência e, ao mesmo tempo, a esconde. A essência se manifesta no fenômeno, mas só de modo inadequado, parcial, ou apenas sob certos ângulos e aspectos. $\mathrm{O}$ fenômeno indica algo que não é ele mesmo e vive apenas graças ao seu contrário. A essência se manifesta no fenômeno. $\mathrm{O}$ fato de se manifestar no fenômeno revela seu movimento e demonstra que a essência não é inerte nem passiva. Justamente por isso o fenômeno revela a essência. A manifestação da essência é precisamente a atividade do fenômeno (KOSIK, 2002, p. $15)$.

Essa relação primordial gera uma conectividade segundo a qual as formas sociais se entrecruzam conformando a totalidade. Ao invés da visão de neutralidade, em que o pesquisador determina ser possível cindir de maneira asséptica o objeto de estudo do mundo 
que o circunda, para assim ser possível estabelecer laços de conexão causais entre este e outras variantes sociais; temos na concreticidade um desenvolvimento segundo o qual a cisão do objeto em relação ao real é o método no qual o objeto só pode ser compreendido como parte imanente do todo social concreto, e onde a conexão do objeto com o mundo circundante se dá mediante uma relação dialética entre as inclinações subjetivas dos indivíduos: os homens são ao mesmo tempo criadores e criados pelo todo social.

\section{QUAL É A PAUTA DA CATEGORIA PETROLEIRA?}

$\mathrm{O}$ ato de produção e reprodução do trabalho petroleiro se desenvolve guardando conexão direta com o produto petrolífero tornado mercadoria. A produção da mercadoria petróleo condiciona relacionalmente a atividade de trabalho petroleira. Em primeira linha temos que o trabalho petroleiro é um trabalho originariamente braçal, derivando que o trabalho petroleiro acaba por ser eminentemente masculino. Da necessidade de produção e reprodução constante da mercadoria petróleo deriva que o trabalho petroleiro é contínuo, sendo necessário a distribuição dos trabalhadores em turnos de trabalho. A produção da mercadoria petróleo requer alterações na natureza das quais derivam o perigo da atividade do petroleiro, por sua vez o perigo da atividade aparentemente reivindicaria uma hierarquização maior da atividade.

O maquinário utilizado para a produção petrolífera requisitou investimentos altíssimos, dessa maneira, no Brasil, o Estado foi o responsável pela produção inicial da mercadoria petróleo, pois era o único em condições de realizar os investimentos. A mesma necessidade de maquinário especializado reivindica uma atividade de trabalho altamente especializada, derivando disso uma categoria aparentemente destacada em relação as outras, com remuneração superior, assim como deriva também uma hierarquização maior do trabalho, ocorrendo divisões entre quem exerce um trabalho mais especializado e do que o outro.

Por qualquer ângulo que se analise, entre as características internas do trabalho petroleiro, conformam-se relações que originam um complexo. De forma que o centro de insurgência do complexo é a atividade humana, o trabalho humano. Para além da relação entre as características, temos um nexo direto entre a atividade de trabalho e o que é produzido pela 


\section{nowite

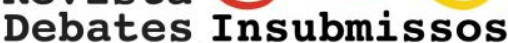

atividade, no caso o petróleo. De forma que a relação aqui entre o homem e a natureza, a relação de transformação da natureza pelo homem, origina derivações que na atividade humana, torna por exemplo tal atividade mais braçal, mais masculina, hierarquizada, de forma a que o trabalho seja produzido e reproduzido.

Esse fluxo constante de produção e reprodução dos pôres teleológicos ${ }^{3}$ originados no trabalho conformam relações sociais cada vez mais complexas ${ }^{4}$. A reprodução é então a forma como paulatinamente relações de intermediação entre o homem e a natureza transformam-se em relações sociais. No nosso caso, a necessidade de obtenção energética requer a realização de atividades de alteração direta da natureza e tais atividades requerem uma complexificação social que tem como base originária a atividade de alteração da natureza.

A questão é que a reprodução desenvolve uma divisão social do trabalho e estrutura uma relação de classe no ser social. Da estruturação da sociedade em classes encontramos que as classes não se constituem em si, mas somente em relação a outras classes. Nesse sentido, Oliveira nos apresenta:

Mas a re-produção não é simplesmente o eterno retorno da produção, que no caso transformariam os resultados em re-posição dos pressupostos. A re-produção é o movimento no qual e pelo qual a objetividade se re-presenta. Re-presentar-se é o reconhecimento da necessidade do outro re-produzir-se pelo e no seu oposto. Noutros termos, o operário para re-produzir-se deve vender sua força de trabalho e comprar os meios de subsistência; este é o momento objetivo de sua inserção na divisão social do trabalho. Mas, não é senão quando ele reconhece o capitalista como sendo aquele que, ilusoriamente - a 'ilusão necessária' - lhe fornece o dinheiro de que ele necessita para comprar os elementos de sua subsistência, que se fundam simultaneamente o operariado e a burguesia. Este é o momento da subjetividade ou da subjetivação da objetividade. A constituição das classes repousa sobre este movimento complexo da produção e da re-produção, e as representações das classes umas visà-vis das outras formam a trama insubstituível das mediações (OLIVEIRA, 1987, p. 12)

\footnotetext{
3 “a teleologia, em sua essência, é uma categoria posta: todo processo teleológico implica o pôr de um fim e, portanto, numa consciência que põe fins. Pôr, nesse contexto, não significa, portanto, um mero elevar-àconsciência, como acontece com outras categorias e especialmente com a causalidade; ao contrário, aqui, com o ato de pôr, a consciência dá início a um processo real, exatamente ao processo teleológico. Assim, o pôr tem, nesse caso, um caráter irrevogavelmente ontológico”. (LUKÁCS, 2013, p.48)

4 "Com efeito, o trabalho enquanto categoria desdobrada do ser social só pode atingir sua verdadeira e adequada existência no âmbito de um complexo social processual e que se reproduz processualmente” (LUKÁCS, 2013, p. 159)
} 
Francisco de Oliveira apresenta que este movimento de reconhecimento da classe é o espaço da política, por consequência, a representação de uma classe perante a outra ocorre de maneira mais expressa no espaço político. No nosso caso temos o seguinte avanço: o ato de produção e reprodução da atividade de trabalho petroleira desenvolve uma divisão social do trabalho e coloca em confronto o petroleiro diante do restante da totalidade social. Dessa complexificação do trabalho temos uma inserção da categoria petroleira na política através de sua pauta de reivindicação.

É necessário então desmobilizarmos visões que concebem categoria classe como um fato social externo aos sujeitos. Nesse sentido Thompson assim entende:

Por classe, entendo um fenômeno histórico, que unifica uma série de acontecimentos díspares e aparentemente desconectados, tanto na matéria-prima da experiência como na consciência. Ressalto que é um fenômeno histórico. Não vejo a classe como uma "estrutura", nem mesmo como uma "categoria", mas como algo que ocorre efetivamente (e cuja ocorrência pode ser demonstrada) nas relações humanas. (THOMPSON, 1987, p. 9)

Thompson apresenta, portanto, uma visão de classe social que se baseia em atos realmente existentes que conformam relações construídas entre sujeitos. O autor continua sua elaboração no seguinte sentido:

A relação precisa estar sempre encarnada em pessoas e contextos reais. Além disso, não podemos ter duas classes distintas, cada qual com um ser independente, colocando-as a seguir em relação recíproca. Não podemos ter amor sem amantes, nem submissão sem senhores rurais e camponeses. A classe acontece quando alguns homens, como resultado de experiências comuns (herdadas e partilhadas), sentem e articulam a identidade de seus interesses entre si, e contra outros homens cujos interesses diferem (e geralmente se opõem) dos seus. A experiência de classe é determinada, em grande medida, pelas relações de produção em que os homens nasceram - ou entraram involuntariamente. A consciência de classe é a forma como essas experiências são tratadas em termos culturais: encarnadas em tradições, sistemas de valores, ideias e formas institucionais. (THOMPSON, 1987, p.10)

Qual é então a pauta de reivindicação da categoria petroleira? Este é o ponto de questionamento do tópico presente.

A fim de avançarmos para a questão é necessário, antes, delinearmos que a pauta da categoria petroleira é derivada diretamente das características que conformam essa categoria. Tais características formam o ser do petroleiro e a partir do seu ser e em oposição a outras classes sociais o petroleiro constrói a sua representação. Temos aqui um trabalho perigoso, 
relacionado a uma indústria estatal, masculino, hierarquizado, contínuo e assim sucessivamente, que tem como resposta a reprodução na política de uma pauta específica que visa alterar a realidade social a partir de interesses entrelaçados entre os trabalhadores petroleiros. Caldeira Brant assim expõe:

A conjugação entre interesses imediatos, referentes às condições de trabalho e salários, e objetivos políticos mais gerais, atinentes à organização do estado, encontra no sindicalismo petroleiro um cenário privilegiado. Por situar-se na Petrobrás, empresa modelo das propostas ao mesmo tempo estatizantes e democratizantes do pós-guerra; por articular a defesa do patrimônio público com reivindicações sobre o controle da gestão empresarial pelos trabalhadores; por arrostas os dilemas entre interesses comuns ao conjunto diferenciado dos vários setores do operariado e interesses daqueles que se situam no polo mais moderno da produção; por atuar em área estratégica do ramo energético; por questionar, enfim, políticas estatais centralizadas que afetam a todos - o exame da atuação dos petroleiros já se revelaria relevante. (CALDEIRA BRANT, 1990, p. 15)

Surge então que a pauta da categoria petroleira é derivada das características que compõem o trabalhador petroleiro e não haveria de ser de outra forma. Porém a pauta é orientada contra quem? Ou em relação a quem? Constrói-se uma relação de mediação entre os petroleiros e a empresa estatal em que o patrão é representado, em última instância, pelo Estado.

Caldeira Brant, ao analisar entrevistas com petroleiros que participaram da greve de 1983, assim expõe como os petroleiros representavam a sua condição de trabalhadores:

\begin{abstract}
O petroleiro nunca se sentiu empregado da Petrobrás. A gente se sentia dono daquilo tudo. Foi ali, com Shigeaki, que começou a mudar isso. A gente começou a perceber que a Petrobrás era patrão. Na primeira reunião com o grupo, entretanto, um militante havia afirmado que 'nós não temos patrão, a gente não sente a situação de patrão contra empregado. Nosso patrão é a Petrobrás. Nosso patrão é todo o povo brasileiro'. Praticamente as mesmas palavras com sentido inverso. $O$ discurso se particulariza de acordo com o universo tratado. Ao falar genericamente da condição de petroleiro, dizse que o patrão é o povo brasileiro. Ao especificar a gestão Ueki, o sentido muda e a Petrobrás, ou a sua administração, é o patrão. Com a greve o patrão passará a ser o 'Sistema' (CALDEIRA BRANT, 1990, p. 40).
\end{abstract}

Em primeiro lugar, encontramos a demarcação que Caldeira Brant faz sobre o entendimento dos petroleiros compreenderem-se como donos da empresa. Em segundo plano, fica demarcado um processo contraditório no reconhecimento do petroleiro enquanto trabalhador, que é derivado justamente da bifacialidade da gestão da empresa. O sentir-se empregado surge justamente na década de 1980, ou pelo menos a memória do trabalhador entrevistado indica que esse sentimento surgiu somente na década de 1980. Tal sentimento é 
sinalizador de que as alterações neoliberais ocorridas nessa década alteraram também a percepção dos trabalhadores petroleiros.

Retornando à questão da representação que o petroleiro faz de si perante a empresa estatal que é objetivamente a sua patroa, encontramos que essa é uma representação ideológica. Ideológica aqui em qual sentido? Lukács traz a seguinte entendimento a respeito de ideologia:

Se agora e mais tarde falarmos de ideologias em contextos mais amplos, estas não devem ser entendidas no enganoso uso atual da palavra (como uma consciência de antemão falsa da realidade), mas, assim como Marx determinou no prefácio da Crítica à economia política, como formas "nas quais os seres humanos se conscientizam desse conflito" (isto é, daqueles que emergem dos fundamentos do ser social) "e o combatem". Essa determinação abrangente de Marx - e esse é o elemento mais importante de sua ampla aplicabilidade - não dá nenhuma resposta unívoca à questão de correção ou falsidade metodológica e objetiva das ideologias. Ambas são igualmente possíveis na prática. Assim, as ideologias em nosso caso podem proporcionar tanto uma aproximação do ser como um afastamento dele. De qualquer modo, porém, tem um grande papel na história do nosso problema o interesse repleto de conflitos dos homens em saber se um momento importante - para eles - de sua vida social deve ser considerado como existente ou meramente aparente. E como tais ideologias, especialmente em tempos de crise da sociedade, podem aumentar tornando-se verdadeiras forças espirituais, sua influência na formulação e solução da questão teórica sobre o ser é considerável (LUKACS, 2010, p.34)

Ideologia de maneira ampliada seria então a representação que os homens fazem do conflito social realmente existente. De forma que, a partir desse conflito, eles enxergam o confronto entre as classes. Meszáros assim compreende o estabelecimento da ideologia no processo de reprodução do metabolismo social:

Na verdade, a ideologia não é ilusão nem superstição religiosa de indivíduos malorientados, mas uma forma específica de consciência social, materialmente ancorada e sustentada. Como tal, não pode ser superada nas sociedades de classe. Sua persistência se deve ao fato de ela ser constituída objetivamente (e constantemente reconstituída) como consciência prática inevitável das sociedades de classe, relacionada com a articulação de conjuntos de valores e estratégias rivais que tentam controlar o metabolismo social em todos os seus principais aspectos. Os interesses sociais que se desenvolvem ao longo da história e se entrelaçam conflituosamente manifestam-se, no plano da consciência social, na grande diversidade de discursos ideológicos relativamente autônomos (mas, é claro, de modo algum independentes), que exercem forte influência sobre os processos materiais mais tangíveis do metabolismo social. (MESZÁROS, 2004, p. 65)

Meszáros prossegue da seguinte maneira:

Nesse sentido, o que determina a natureza ideológica, acima de tudo, é o imperativo de se tornar praticamente consciente do conflito social fundamental - a partir dos pontos de vista mutuamente excludentes das alternativas hegemônicas que se 


\section{Revista \\ Debates Insubmissos}

defrontam em determinada ordem social - com o propósito de resolvê-lo pela luta. (MESZÁROS, 2004, p. 66)

Assim podemos desenvolver que a reprodução subjetiva na consciência dos petroleiros dos aspectos maiores e mais abrangentes do conflito realmente existente em torno da questão do petróleo, da Petrobras, e todas as consequências políticas decorrentes desses conflitos, têm uma ancoragem material específica. $\mathrm{O}$ trabalho petroleiro tem prioridade para determinar essa ancoragem: a produção e reprodução dos atos que tem como pôr teleológico a obtenção de óleo constituem características do trabalho petroleiro que formam, como já vimos, um complexo.

Surge então a questão da consciência ideológica a respeito do conflito existente que contrapõe petroleiros em face da empresa petrolífera. Tal questão não surge somente do ato de reprodução do trabalho, mas sim, nos termos de Meszáros, a partir do propósito de resolver o conflito objetivamente existente pela luta.

A movimentação ideológica, no entanto, não deve ser encarada somente como um impulso contestador da ordem interna ao trabalho, mas também como um desenvolvimento conservador dos próprios trabalhadores no sentido de reforçar efeitos nefastos da relação de trabalho. Dessa maneira encontramos que nas origens, como relata Oliveira Júnior (1995), os petroleiros pioneiros não paravam de trabalhar. Se ocorresse acidente, a não ser que o acidente fosse grave, não paravam por "coisa pouca", porque "o trabalho seria de homem".

Nesse ponto o machismo era acionado como impulso ideológico para que condições de trabalho adversas fossem toleradas. Entretanto o maior impulso ideológico instrumentalizado para o apaziguamento do conflito de classes no trabalho petroleiro era o derivado do nacionaldesenvolvimentismo, como bem narrado pela petroleira Wanda:

Outra coisa que diferencia a Petrobrás por ser estatal é a luta do petróleo é nosso, então você tinha um orgulho de trabalhar num lugar que o brasileiro tinha lutado, que o petróleo era muito importante. $\mathrm{O}$ funcionário da Petrobrás era muito orgulhoso de ter contribuído no Brasil para essa luta do Petróleo é nosso. Isso era evidente. Quando nós entramos na Petrobrás... agora não sei. Quando nós entramos, a gente fazia todo o sacrifício para a Petrobrás ir para frente. A gente até se sacrificava mais do que... muita gente trabalhava até além sem receber hora extra, muitas vezes, sem nada, mas 


\section{nowite

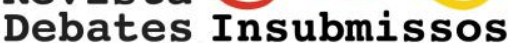

pela alegria de estar contribuindo com uma empresa brasileira e do porte do petróleo... de porte grande, dentro da Petrobrás. Acho que isso pesava muito para nós ${ }^{5}$.

Encontramos então que o nacionalismo era instrumentalizado como meio de extensão e intensificação da jornada de trabalho, o sacrifício dos trabalhadores era feito em função de construir com suas mãos uma empresa nacional, às vezes até mesmo sem receber por esse trabalho a mais. A pauta da categoria petroleira configura então o enlace entre o ato de trabalho e a representação ideológica que o petroleiro faz do conflito de classes objetivamente existente na sociedade.

O conflito de interesses tem em vista a concretização de uma alteração nas relações de poder internas ao trabalho, seja quando determina um aumento da massa salarial, seja quando interfere no poder hierárquico existente no trabalho. É de interesse dos petroleiros alterar a distribuição do excedente no processo de produção do capital petrolífero, de forma que o excedente seja distribuído de maneira mais benéfica aos mesmos. Esse interesse, que é um interesse coletivo, expressa-se de forma concreta na pauta. Qual é então a pauta dos petroleiros? Deyvid Bacelar sintetiza a pauta petroleira do seguinte modo:

A pauta acaba sendo distinta né, mas, hoje a nossa campanha indicatória, foi conseguida dessa maneira que a gente está conversando aqui, estão em 3 eixos que tanto faz seja a nossa ou da FNP que a gente conseguiu construir algo em conjunto. Tem 3 eixos, o primeiro, da defesa da liberdade e autonomia sindical, que está sendo atacado pelo governo Bolsonaro, por tabela pelas gestões das empresas públicas e estatais, dentre elas a Petrobrás. É primeiro isso, a gente viu essa parte, com relação as contribuições sindicais, onde a Petrobrás é a primeira empresa a cortar as mensalidades, é o direito que o trabalhador tem de escolher de se associar ao sindicato, ele pode dizer para onde o dinheiro dele vai, descontado no contracheque, então foi a primeira empresa a fazer isso, atacou já a reforma trabalhista a questão do imposto sindical, e além das contribuições das cotas sindicais com uma série de dificuldades para acertar esses recursos que os trabalhadores aprovam em assembleia, então a gente tem esse eixo na campanha reivindicatória ${ }^{6}$.

Deyvid divide a pauta, como veremos, em três eixos: o primeiro relacionado à liberdade sindical; o segundo relacionado aos direitos trabalhistas da categoria petroleira; e o último relacionado à defesa da empresa pública. Essa estruturação cumpre com uma perspectiva na qual em primeiro lugar surge o direito a reivindicar direitos.

\footnotetext{
${ }^{5}$ Entrevista realizada pelo pesquisador em 10/02/2019

${ }^{6}$ Entrevista realizada pelo pesquisador em 10/10/2019
} 
A questão da autonomia sindical é relacionada à possibilidade do trabalhador petroleiro poder se organizar politicamente para defender a sua pauta perante a empresa. É concretizada a defesa da autonomia sindical na fala de Deyvid a partir da análise das alterações legislativas que, desde o governo Temer com a reforma trabalhista, atingem o financiamento dos sindicatos:

O outro eixo é a defesa dos direitos históricos na categoria petroleira, nós temos um acordo coletivo de trabalho, ao longo desses 66 anos, que foi muito melhorado nesses anos 2003 a 2014 especificamente nesses anos, onde a gente teve um avanço não só na remuneração, com ganho real de salário, acima dos $40 \%$ acima da inflação e mais de 45 clausulas que foram inseridas no acordo coletivo de trabalho, então hoje, devida a mudança do governo federal, a gente tem um ataque a esses direitos históricos e a gente tem ciência que esse o acordo coletivo de trabalho ele sendo destruído ou piorado, isso reflete por tabela nas demais empresas públicas e estatais, e falo do primeiro eixo, liberdade e autonomia sindical, defesa da nossa organização, segundo a defesa dos direitos da categoria petroleira e o terceiro eixo que é a defesa do sistema Petrobrás, essa empresa integrada e construída, nesses anos principalmente nos governos de Lula e Dilma ela está sendo atacada, no sentido dela se tornar ou voltar a ser apenas uma empresa de exploração e produção de petróleo e gás e apenas o présal brasileiro, essa sem dúvida alguma, é a principal bandeira, o principal eixo, dessa conferência sindical que arrasta aí desde o dia 15 de maio a gente já está chegando no final do ano ${ }^{7}$.

Assim, a defesa da autonomia sindical garante a possibilidade de os petroleiros buscarem proteger os seus direitos, ao passo que a defesa do caráter público da Petrobras tem uma relação íntima com a defesa dos direitos trabalhistas dos petroleiros.

\section{COMO OS PETROLEIROS REIVINDICAM SEUS DIREITOS?}

A pauta defendida pelos petroleiros compõe o quadro daquilo que representa "o que" os petroleiros querem. Partindo-se então do emaranhado de vontades humanas dos trabalhadores petroleiros surge então um elenco objetivo das alterações que eles pretendem ver realizadas no mundo, ou das alterações que eles pretendem que não sejam realizadas no mundo.

Essas vontades são então históricas, de forma que em uma quadra histórica favorável o que se reivindica é um avanço dos direitos consolidados, ao passo que numa quadra histórica em que a conjuntura não é favorável, reivindica-se a permanência dos direitos conquistados. Numa quadra histórica favorável, temos o avanço dos salários, do número de empregados, das

\footnotetext{
${ }^{7}$ Entrevista realizada pelo pesquisador em 10/10/2019.
} 


\section{Revista \\ Debates Insubmissos}

vantagens e benefícios, ao passo que em uma quadra histórica adversa, enxergamos a resistência da categoria petroleira para manter os direitos consolidados.

Consequentemente, assim como o ato de realizar trabalho pressupõe alterações no mundo real, pressupõe movimentos realmente existentes, essa movimentação ocorre de uma forma dada socialmente. Se um petroleiro tem um turno de trabalho de 8 horas e não de 12 horas, ou se ele é obrigado a permanecer no posto por duas horas até ser rendido pelo turno posterior essa é uma organização social do modo de realização do trabalho. O trabalho altera o mundo natural, a reivindicação trabalhista tem como finalidade alterar o modo como é realizado o trabalho. Altera-se a quantidade de valor revertida em salários, altera-se a quantidade de tempo de trabalho a que o trabalhador se submete, alteram-se os equipamentos de proteção concedidos, e assim sucessivamente.

Aqui encontramos que as formas de mobilização para a reivindicação dos direitos pelos petroleiros não dizem respeito ao "o que" se reivindica, mas sim ao "como" se reivindica. De uma certa maneira são análises que aparecem atravessadas e não é possível tratar do acordo coletivo de trabalho sem tratar, por exemplo, do anúncio de greves por parte das federações sindicais dos petroleiros. Mas a questão aqui é a conexão existente entre "o que" os petroleiros querem garantidos a título de direitos e "como" os petroleiros querem garantir os seus direitos.

Qual a conexão entre a pauta de direitos dos trabalhadores petroleiros e como esses trabalhadores pretendem fazer essa pauta? Em primeira linha, é importante apontar a distinção entre forma e conteúdo. A forma como se apresentam as vontades dos petroleiros compõe tanto a objetificação na pauta em que são enumeradas as vontades coletivas da categoria, quanto a forma como se pressiona para que essa pauta avance, mas ao fundo temos um conteúdo unificador. Qual é o conteúdo que tem a primazia de influenciar tanto o elenco de demandas quanto a maneira como os petroleiros escolhem para pressionar por essas demandas? É então a redistribuição do excedente de valor.

A produção de valor requer a exploração do trabalho e a remuneração do trabalho abaixo do valor produzido; assim, o excedente surgido é a finalidade última da exploração do trabalho no capitalismo. A redistribuição desse excedente é o conteúdo último de todas as reivindicações 


\section{Revista \\ Debates Insubmissos}

da categoria petroleira: surge na reivindicação de salários maiores, na reivindicação de turnos com menos horas de trabalho, na de maior remuneração de horas extras de trabalho, em que são mais evidentes, mas também surge em pautas que não necessariamente dizem respeito ao salário ou ao tempo de trabalho, como por exemplo, a pauta relacionada ao acidente de trabalho. Aqui, se é do interesse do petroleiro que ele se acidente menos, é necessário que a empresa realize gastos maiores com equipamentos de proteção, treinamento e manutenção do maquinário.

Em essência então a reivindicação da categoria petroleira é uma redistribuição mais vantajosa do excedente de valor, essa demanda essencial tem sua aparência nos objetivos elencados na pauta (maiores salários etc.) e na forma como essa pauta vai ser reivindicada. Aparência e essência conformam uma dualidade em que a existência de uma depende da outra: só existe o pleito pela redistribuição do excedente de valor em essência em razão de existir as várias formas aparenciais dessa demanda, de forma que o pleito essencial condiciona a forma como este vai aparecer.

A mesma relação encontramos, por exemplo, quando analisamos a estruturação do trabalho petroleiro de maneira hierárquica, continua, e assim sucessivamente: tal trabalho aparece estruturado dessa maneira, no entanto o amálgama que faz com que ele seja produzido e reproduzido assim no capitalismo deriva centralmente da produção de excedente de valor.

Para além da distinção entre o conteúdo unificador da pauta dos petroleiros temos que apreender que as formas de mobilização dependem da utilização de meios para se atingir determinado fim. Da mesma maneira o trabalho humano, ao alterar a natureza, necessita determinar quais meios utilizará para atingir o fim pretendido. Aqui encontramos a importância do correto espelhamento da realidade, agora transposta para se atingir objetivos que são puramente sociais.

Por outro lado, concretamente o trabalho serve como modelo da práxis social ${ }^{8}$. Dito de outra maneira, a consciência humana desenvolve meios para acionar os corretos nexos causais

\footnotetext{
${ }^{8}$ Nossas últimas exposições mostraram como nos pores do processo de trabalho já estão contidos in nuce, nos seus traços mais gerais, mas também mais decisivos, problemas que em estágios superiores do desenvolvimento humano se apresentam de maneira mais generalizada, desmaterializada, sútil e abstrata e que por isso aparecem
} 


\section{nevitate

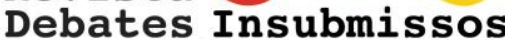

na natureza através do trabalho, e de maneira similar, ela pode desenvolver meios para fazer valer sua vontade social. Responder quais são os meios utilizados pelos petroleiros para fazer valer suas demandas coletivas equivale a responder como os petroleiros reivindicam a sua pauta.

Temos ainda que trazer à tona a reflexão sobre a visão ideológica, na conceituação de ideologia em seu sentido ampliado, quando tratamos de questionar "como" os petroleiros reivindicam seus direitos. A visão ideológica que os petroleiros têm da sociedade surge no mesmo passo dos enfrentamentos reais entre eles e os seus patrões. Compreende-se então que a forma como se faz esse enfrentamento molda a visão ideológica do trabalhador petroleiro, ao colocá-lo diante de problemas a serem resolvidos na luta social, sem os quais ele não poderia prescindir para a formação de sua própria consciência enquanto trabalhador.

O passo seguinte para avançarmos nas considerações a respeito das formas de reivindicação da categoria petroleiro por direitos é levarmos em conta o desenvolvimento da organização sindical petroleira.

Não pretendemos realizar um histórico, o que seria inviável, das organizações sindicais de petroleiros. A questão é que, historicamente, a organização do trabalho petroleiro deriva, o que é uma tremenda obviedade, da existência de trabalhadores petroleiros a se organizarem. Assim o Sindicato dos Petroleiros na Bahia surge em razão da construção da refinaria Landulpho Alves em Mataripe, ao mesmo tempo que o Sindicato dos Petroleiros em Cubatão surge em razão da construção da Refinaria Presidente Bernardes na região.

A hierarquia excessiva na refinaria gerava uma atmosfera de solidariedade entre os petroleiros, bem como a oposição entre os peões e os técnicos engenheiros também estimulava a solidariedade entre os peões. Consequentemente essa solidariedade refluiu para um espaço social, que foi inicialmente as associações e depois os sindicatos.

A opressão sentida individualmente pelo trabalhador petroleiro, muitas vezes humilhado, agredido, colocado numa atmosfera de subalternização militarizada acaba

depois como os temas centrais da filosofia. É por isso que julgamos ver no trabalho o modelo de toda práxis social (LUKÁCS, 2010, p. 83) 
Revista

Debates Insubmissos

encontrando espaço de reconhecimento e representação na sociabilidade sindical. É nesse ponto que encontramos a razão finalística do sindicato: fazer com o que o trabalhador sinta que não está sozinho, que existem outros que sofrem dos mesmos problemas que ele. Machado nos conta como alguns trabalhadores tinham medo até de se dirigir aos superiores:

[...] e muitos deles que eu conhecia na época, muitos trabalhadores temiam se por acaso soubessem que ia ter uma reunião com algum gerente, não era nem gerente do alto escalão e comando, o cara já tremia todo 'não rapaz por que vai ter reunião com gerente tal' aí você percebia né que tinha essa distância, esse gestão assim de alto poder, eu tô em cima, você tá embaixo e você não tem nada, só ser por acaso você pular essa parte ou for agraciado com algum prêmio, alguma coisa assim ou você vai ser demitido, por que você fez algo muito sério e vai ser demitido pelo gerente geral, tipo o militar que vai desertado e tem todo aquele ritual por que vai desertar o cara, era algo assim indescritível aí todo mundo da unidade já sabia que ia ser demitido e era um constrangimento e não tinha um negócio de você saber, ficar em dúvida ou não, ia ser demitido e acabou ${ }^{9}$.

O temor que Machado detalha é reflexo da hostilidade existente entre trabalhadores e gerentes. A hostilidade então se generaliza, desde o temor e o distanciamento entre gerentes e petroleiros até atitudes individuais de resistência ao comando. São vários os relatos, por exemplo, de que eram comuns agressões, dentro e fora das refinarias e postos de trabalho, entre peões e engenheiros, ou entre chefias e petroleiros, nos primeiros anos de produção de petróleo no país. A exploração do trabalho engendra então uma hostilidade, uma oposição hostil entre trabalhadores e gerentes, essa hostilidade terá expressão concreta mais ampla a partir da organização dos trabalhadores. A respeito da questão de que o sistema em si de dominação normalmente embute uma processualidade de humilhações, Scott traz a seguinte reflexão:

parece-nos bastante claro que um subordinado prudente tende a conformar o seu discurso e os seus gestos àquilo que sabe que dele se espera - mesmo que essa submissão mascare uma opinião muito diferente daquela que é revelada fora de cena. O que nem sempre é tão claro é que, em qualquer sistema de dominação estabelecido, o problema não se resume à dissimulação dos sentimentos e à produção dos adequados actos discursivos e gestuais no lugar deles. Trata-se, antes de mais, de controlar o que seria um impulso natural para a revolta, a agressividade, a raiva e a violência que esses sentimentos normalmente desencadeiam. Não existe nenhum sistema de dominação que não engendrar a sua safra diária de atropelos e atentados à dignidade humana: apropriação do trabalho, humilhações públicas, fustigações, violações, bofetadas, assédios, desprezo, rituais de denegrimento, etc (SCOTT, 2013, p. 71)

\footnotetext{
${ }^{9}$ Entrevista realizada pelo pesquisador em 27/10/2019.
} 
Revista

Debates Insubmissos

Scott produz uma análise teórica na qual há a oposição entre o discurso público e o discurso oculto, em que o discurso oculto é aquele reproduzido fora de cena. Os gestos e atos discursivos dos dominados desenvolvidos publicamente representam então uma ocultação da hostilidade que só vai se tornar aparente a partir da organização coletiva. Quando se trata dos trabalhadores petroleiros essa dualidade entre discurso público e oculto aqui se apresenta, consequentemente o espaço prioritário para a organização desses trabalhadores é o sindicato. É através da sociabilidade sindical que a hostilidade individual entre gestores e petroleiros se transforma em uma hostilidade coletiva entre a categoria petroleira e a empresa.

Para esse processo de organização coletiva dos trabalhadores a assembleia cumpre uma função essencial. Fábio Melo trata a respeito de como ocorrem as assembleias na sua base sindical dessa maneira:

\begin{abstract}
Vou te falar como funciona aqui no litoral paulista, tá? Aqui no litoral paulista as nossas assembleias funcionam da seguinte forma, pessoal de plataforma tem um calendário de assembleia um pouco mais elástico e as assembleias são feitas ou no embarque ou a bordo. Os trabalhadores mesmo que organizam porque a gente não tem como embarcar diretores pra tá organizando isso. A gente manda a lista pra eles com a deliberação e eles colhem os votos dos trabalhadores... em plataformas funciona dessa forma. Já em terra, as assembleias são marcadas em um único dia, por quê? Porque aqui no litoral paulista a gente tem uma tradição de as assembleias serem na sede do sindicato. Então por exemplo a assembleia é amanhã, pra deliberar se vai ter greve ou não, ou se vai aceitar ou não um acordo, como é que funciona? Nós temos uma subsede que atende o litoral norte e o pessoal que mora no litoral norte tem como chegar na subsede, que acontece por videoconferência. O pessoal da RPBC, do terminal de alemoa e os que trabalham embarcados, mas estão de folga, vem para a sede do sindicato nesse dia. É amplamente divulgado, você põe no jornal e tudo mais. Os trabalhadores que estão impedidos de vir porque estão trabalhando, é o pessoal que tá no turno às 18 , porque geralmente é às 18 horas que a assembleia começa, o pessoal que tá de 15 a 23 eles não poderiam participar da assembleia porque estão trabalhando, o que a gente faz? A gente vai lá e colhe voto, faz assembleia na porta da fábrica pra esses trabalhadores ${ }^{10}$.
\end{abstract}

A divisão desenvolvida conecta-se com o trabalho realizado pelo petroleiro, a assembleia se amolda à realidade do trabalho: se é trabalhador das plataformas, a assembleia ocorre de uma forma, se é trabalhador em terra, de outra; se o petroleiro trabalha no litoral norte, se encaminha para uma sede do sindicato, se trabalha na região da refinaria, se encaminha para

\footnotetext{
${ }^{10}$ Entrevista realizada pelo pesquisador em 26/12/2019.
} 
outra; se o trabalhador está de folga ou fora do seu turno de trabalho, vem até a sede do sindicato, se o trabalhador está no turno de trabalho, a assembleia é feita no local onde trabalha.

$\mathrm{Na}$ assembleia o sentimento de coletividade apresenta-se. $\mathrm{O}$ trabalhador isolado no turno de trabalho pode ter receio de reagir ao gerente, receio de enfrentar a empresa, o temor que Machado detalhou. Mas em assembleia, com mais de mil trabalhadores, discutindo coletivamente qual é a intervenção que será realizada, o poder do trabalhador torna-se outro. Ele sabe que qualquer ação não é mais atitude individual e sim uma força coletiva de milhares de vontades. No entanto Scott apresenta que somente a existência de um espaço onde "as réplicas e afirmações omitidas pelo subordinado possam ser articuladas em segurança" (SCOTT, 2013, p. 168), avançando para a análise teórica de que é necessário a formulação de uma contra-ideologia, uma forma de negação da ideologia dominante:

\begin{abstract}
As práticas de resistência podem mitigar o peso dos mecanismos quotidianos de apropriação material e os gestos de negação expressos no discurso oculto podem contestar os insultos diários à dignidade dos subordinados. Mas no plano da doutrina social sistemática, os grupos subordinados enfrentam ideologias complexas que justificam a desigualdade, a subjugação, a monarquia, as castas, etc. Neste plano, a resistência requer uma resposta mais elaborada, uma resposta que vá além das práticas de resistência fragmentárias. Dito de outra forma, a resistência à dominação ideológica requer uma contra-ideologia - uma negação - capaz de oferecer uma forma normativa geral e efectiva às múltiplas práticas de resistência que os grupos subordinados inventam para se defender (SCOTT, 2013, p. 171).
\end{abstract}

No que se refere à questão petroleira, a perspectiva mais ampla de orientação normativa em direção à uma negação ideológica da dominação sobre o trabalho exercido pela empresa se expressa no sentido de uma ideologia sindical. Aqui, vocabulários, gestos, maneiras de pensamento desenvolvem de forma geral uma perspectiva de contra-ofensiva que se investe contra a dominação exercida contra os trabalhadores.

Se o desenvolvimento da vontade coletiva é apreendido pela empresa, e ela aceita dialogar no sentido de garantir os direitos pleiteados, temos cumpridas as finalidades da sociabilidade sindical. Mas o que acontece se não há abertura para o diálogo? Temos então que os petroleiros precisarão pressionar para verem garantidos seus direitos. Quais são as formas de pressão? Assim Jorge Braga sintetiza as formas de mobilização dos petroleiros:

Aqui a gente tem modelos meio que consolidados por assim dizer, né? O primeiro deles é o movimento paredista, trancaço, paralisação, não deixar as pessoas entrarem 


\section{Revista \\ Debates Insubmissos}

na base. E isso de uma certa forma, não sei em qual movimento se dá mas... veio perdendo de certa forma a força porque as pessoas passam a ter uma disputa ideológica na base para participar ou não das coisas, não sei explicar bem o quê que aconteceu. Mas um dos modelos é o trancaço, né, não deixar as pessoas entrarem, paralisar ou por um dia né, que a gente chama de movimento de paralisação, ou entrar em processo por tempo indeterminado ${ }^{11}$.

A partir da definição coletiva de que se deve pressionar a gestão da empresa pela garantia de um determinado direito ou pela ampliação de direitos, se instaura o processo de movimento grevista. Nem todos os petroleiros participam da mobilização, e fica expresso na fala de Braga que de uns tempos para cá, por conta da disputa ideológica na base, vem "perdendo a força" esse tipo de mobilização. Ou seja, parcelas da categoria não se sentem mais movidas ideologicamente a realizar esse tipo de pressão. Nesse ponto é de importância demarcar a diferença existente entre relações de classe e consciência de classe, distinção que Thompson oferece da seguinte maneira:

A classe acontece quando alguns homens, como resultado de experiências comuns (herdadas ou partilhadas), sentem e articulam a identidade de seus interesses entre si, e contra outros homens cujos interesses diferem (e geralmente se opõem) dos seus. A experiência classe é determinada, em grande medida, pelas relações de produção em que os homens nasceram - ou entraram involuntariamente. A consciência de classe é a forma como essas experiências são tratadas em termos culturais: encarnadas em tradições, sistemas de valores, idéias e formas institucionais. Se a experiência aparece como determinada, o mesmo não ocorre com a consciência de classe. (THOMPSON, 1987, p. 10).

O movimento paredista é determinado pelo tempo. Pode ser uma paralisação de algumas horas, de um dia, ou por tempo indeterminado. A pressão serve então para impedir os trabalhadores que não estão participando do movimento de entrarem no posto de trabalho.

Braga continua o relato:

Daí a gente entra numa situação no movimento paredista que a gente tem que fazer escolhas no sentido de... se vai fazer uma paralisação total, se vai... O que a gente busca no geral, pra ter impacto sobre a produção é... as pessoas que não tem como participar desse movimento de fábrica, levar essas pessoas à exaustão, manter o mínimo de operadores dentro da fábrica, de forma a inviabilizar que elas se mantenham operando. Mas pra isso requer um tempo também, uma maturação que dificulta o processo de mobilização. Mas basicamente paralisação é um método, a gente fazer atrasos de entrada, né, ao longo da mobilização fazer como se fosse um esquenta. Você faz assembleias onde você atrasa a entrada das pessoas, causa um impacto de algumas horas ali no processo porque demora para se mobilizar, né? Você fazer intervenção na indústria, você tem que chegar cedo, pra poder o serviço não

\footnotetext{
${ }^{11}$ Entrevista realizada pelo pesquisador em 26/09/2019.
} 


\section{nowite

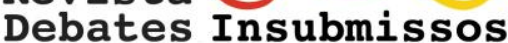

conseguir rodar, quando você faz isso... uma paralisação nas primeiras horas do dia aí, isso gera muito impacto nessa organização dessa estrutura.

Aqui aparece na narrativa de Braga a finalidade última do movimento paredista: paralisar a produção. Impedir o processo de produção da mercadoria petróleo. De forma que, havendo trabalhadores que não tenham aderido à mobilização, a estratégia é levar esses trabalhadores “à exaustão". Mas não é só o bloqueio total da entrada que é utilizado, também é possível atrasar a entrada de forma a fazer com que se perca algumas horas de produção. Dessa maneira o processo de paralisação tem uma gradualidade, um "esquenta", em que aos poucos se vai convencendo os trabalhadores a pararem, vai se criando um ambiente propício para que se pare a produção. Assim, aos poucos se vai fazendo o necessário para que se tenha o mínimo de trabalhadores dentro da planta.

Aqui retornamos à discussão a respeito da relação entre forma e conteúdo. O conteúdo da reivindicação petroleira é a redistribuição do excedente de valor, e esse conteúdo aparece na forma da pauta, aparece também ao sindicato escutar os trabalhadores e eles oferecerem o que eles querem para melhorar sua condição de trabalho, seu ganho salarial e assim por diante. Mas, para além disso, aparece aqui uma conexão nas formas de reivindicação da categoria petroleira que é o impacto direto ou indireto na produção. Em essência é dito: ou o excedente de valor é redistribuído ou então esse excedente que é produzido por nós não será produzido.

No entanto não é somente a forma de reivindicação que decorre do conteúdo geral mas também os modos de dominação exercidos pela empresa tem como finalidade maior a estabilização do processo de produção de valor. Scott apresenta da seguinte maneira a relação existente entre aquilo que ele chama de "apropriação material" e de "experiência social do ultraje":

Tal como se pode considerar que a análise marxista tradicional privilegia a apropriação das mais-valias enquanto espaço social da exploração e da resistência, também a análise que aqui fazemos parece privilegiar a experiência social do ultraje, do controlo, da submissão, da humilhação, da deferência forçada e do castigo. Esta definição de prioridades não pretende contestar a importância da apropriação material nas relações de classe. A apropriação é, afinal de contas, o grande propósito da dominação. Não obstante, o processo de apropriação acarreta inevitavelmente relações sociais sistemáticas de subordinação que impõem humilhações de diversa natureza sobre os mais fracos. Estas humilhações são a semente da revolta, da indignação, da frustração e da bílis acumulada que alimentam o discurso oculto (SCOTT, 2013, p. 163) 
Revista

Debates Insubmissos

As formas de dominação e de reivindicação conectam-se então internamente através do conteúdo inerente a estas. O fim é redistribuir o excedente, e esse fim condiciona as formas de aparecimento das reivindicações. Radiovaldo desenvolve como as reivindicações aparecem em maior intensidade e número na época da negociação do acordo coletivo, aparecendo de maneira residual em outros momentos, o que realça a interligação entre a forma de aparecimento das reivindicações e o seu conteúdo que é a redistribuição do valor:

Bem, ao longo desses anos todos, na verdade a principal pauta de reivindicação sempre foi a renovação do acordo coletivo de trabalho nacional, anual com data base em setembro então sempre a maior demanda o momento de maior crise ou de mobilização, reivindicações e greve sempre foi atrelado à nossa base atrelado justamente durante a renovação do processo de acordo já que sempre também a direção da Petrobras colocava dificuldades, não atendias às reivindicações ou até em alguns casos, tentava retirar algum direito, então nesses anos que você tinha as negociações do acordo é por isso que a gente tinha praticamente uma greve a cada ano. E essa greve a cada ano acontecia justamente no momento das negociações coletiva da renovação desse acordo que era um acordo nacional negociado pela FUP lá atrás, bem atrás, quando eu cheguei, pelos sindicatos de forma desordenada, mas quando a FUP foi constituída, se eu não me engano em 93, aí sim a negociação passou a ter um ordenamento melhor e uma negociação mais centrada na renovação para poder justamente ter é... um resultado prático mais efetivo e também com isso passou a ter um resultado melhor as negociações, muitas reivindicações foram atendidas, muitas reivindicações foram consolidadas em função desse pleito. Agora pontualmente, aconteceram também greves mais de orientação das centrais sindicais, greves gerais, greves contra até um determinado posicionamento do governo, uma determinada pauta mais geral também, mas o nosso movimento mais intenso sempre foi em função da renovação ou das negociações do acordo coletivo ${ }^{12}$.

Assim temos as conexões com o modo de funcionamento dos espaços de produção da mercadoria petróleo. Em primeira linha a necessidade de produção ininterrupta dos derivados de petróleo requerem instrumento legal que obriga a produção mínima necessária para o restante do ser social. Em segunda linha a organização do trabalho em turnos faz com o que no ato de paralisação os trabalhadores que estejam dentro da planta produtiva eventualmente continuem lá. $\mathrm{O}$ ato de fechamento da fábrica impele os trabalhadores que fiquem dentro do posto de trabalho ao cansaço, como bem pontuou Jorge Braga quando disse que a tática utilizada é levar esses trabalhadores à exaustão. Até que a refinaria "é paralisada" pela gerência. Ou seja, o fato de que o trabalho seja realiza continuamente pelo maquinário requer trabalhadores para

\footnotetext{
${ }^{12}$ Entrevista realizada pelo pesquisador em 10/10/2019
} 
acompanhar o processo produtivo. Quando esses trabalhadores são levados ao cansaço, não havendo possibilidade da continuidade, a refinaria é paralisada por vontade da chefia.

Além de determinar o processo de paralisação na refinaria, Abade também delineia o processo de paralisação nos poços de petróleo, onde lá a intervenção na realidade é o fechamento do poço. O peão fecha o poço e entrega a chave ao gerente da ocasião. Isso nos leva ao exercício de correlacionar que em cada processo produtivo o modo de paralisação se expressa de uma forma diferente, desde a extração do petróleo até a distribuição. Tratando da greve de 1983 a petroleira Wanda nos dá um cenário ampliado do processo desde o princípio:

Nós tomamos conhecimento deste documento que levava a refinaria a corte de pessoal e até a privatização, então nós começamos a fazer assembleias, começamos a fazer reunião por turnos, porque na refinaria é difícil né, não e assim, todo mundo trabalha de dia e de noite está livre. Então nós tínhamos que fazer reunião que as pessoas pudessem participar. São quatro turnos de trabalho. Uma que o turno um e dois pudesse participar outra que o três e quatro, outra que o administrativo, quer dizer nós tínhamos que fazer... Então nós fizemos vários encontros no sindicato, tentando conscientizar o pessoal desta situação que nós estávamos sendo encaminhados. Enquanto isso o sindicato tentava fazer gestões com a direção da Replan no sentido de tentar avançar um pouco para que não fosse aplicado este documento. E também quando nós vimos que a situação estava estrangulando de tal forma que nós não tínhamos mais saída, então nós fizemos assembleias, assembleias que pudessem abranger todos né, todos os empregados pudessem participar, não só uma assembleia mas várias, e nessas assembleias nós colocamos em votação a greve, greve geral. E aí, no final, na conclusão de todas estas assembleias, houve um consenso que todos os trabalhadores (todos, a maioria né, os que iam a assembleia, tinham muitos que não iam) que votaram pela greve geral. Então nós fomos pra greve geral. Nós então paramos $^{13}$.

Ao final, o relato da greve de 1983 de Wanda sintetiza toda a processualidade do "como" ocorrem as reivindicações dos petroleiros. Desde as assembleias para definição do que fazer, passando pela utilização do saber petroleiro para realizar a paralisação da produção, e chegando até a disputa travada pelos trabalhadores. A Wanda explica ainda qual é a razão pela qual ela acredita que as greves ocorrem:

Então eu acho que as greves ocorrem porque não existe uma possibilidade de negociação transparente. Porque a gente não consegue ter uma negociação onde os patrões não façam falcatrua, não façam fraude, então existe um esgotamento de negociação. As greves acontecem por quê? Você vai negociando, você vai reunindo, você vai trazendo a proposta da categoria, a categoria não aceita volta para a negociação com a direção, com a categoria, chega uma hora que esgota, chega uma hora que a categoria percebe que a direção não vai ceder nas questões que são os

\footnotetext{
${ }^{13}$ Entrevista realizada pelo pesquisador em 10/02/2019.
} 


\title{
Revista \\ Debates Insubmissos
}

pontos fundamentais para a categoria. Porque só com as máquinas paradas é que nós conseguimos que a direção leve a gente a sério. Teve uma vez acho que foi o Delfim Neto, que falou que os trabalhadores gostam de fazer greve. É mentira. É mentira. Eu não conheci nenhum trabalhador que tenha dito que gostou de fazer greve. $\mathrm{O}$ trabalhador só faz greve quando ele não tem mais capacidade de negociação. Então quando você percebe que esgotaram-se os argumentos e que mesmo assim a direção não abre para continuar a discussão, então, você fala, agora é só parando. Porque parando... É a mesma coisa que multa. No trânsito você é desobediente, mas se tiver um guarda multando você obedece. No lugar que você sabe que tem radar, você obedece a velocidade, porque você sabe que o radar vai te multar, então é só parando que a diretoria reabre de novo a negociação ${ }^{14}$.

A greve é então, para Wanda, um rasgo em relação à negociação. É o ponto em que não existe mais possibilidade de negociação, quando o trabalhador sente que se ele não reagir perderá. A analogia encontrada por ela é a analogia com a multa que é dada a um carro, ou seja é a analogia da punição. Nesse sentido é a punição coletiva, ou a organização coletiva da hostilidade que os trabalhadores acumulam em relação à empresa para que a empresa pare de avançar sobre os direitos dos trabalhadores. A finalidade da mobilização grevista aqui tem a finalidade de reabrir a negociação, para que os direitos sejam consolidados. A outra perspectiva observada na caracterização de Wanda é que a greve é um processo duro, difícil, em que os

trabalhadores são colocados sob pressão, o que é complementado da seguinte forma abaixo:

\begin{abstract}
Então os trabalhadores fazem greve depois de ter esgotado todos os argumentos possíveis e ter visto que não existe possibilidade de chegar num mínimo entendimento. No mínimo que fosse. Não tem possibilidade. Então, aí não tem outra coisa a fazer senão parar, porque parece. Parece não, é verdade. A única coisa que move os capitalistas, os grandes donos do poder é o prejuízo no bolso. Então os trabalhadores só fazem greve porque eles chegaram a um esgotamento da negociação e não consegue. Chega num ponto que não avança mais. As pessoas se esgotam, ou voltam a trabalhar de cabeça baixa, ou faz a greve. Chega num momento que não tem mais o que fazer. Então a greve é o resultado do esgotamento desta negociação. Porque aí o trabalhador não quer voltar às condições que ele tá dizendo que não são boas. Ele não quer voltar de cabeça baixa e ganhar nada. Então, ele tem que... Medida última, de extrema força e violência, mas porque o trabalhador não vê outra possibilidade. Não é porque o trabalhador gosta. É porque o trabalhador não consegue sensibilizar o patrão senão com a greve. E nem que ele sensibilize com a greve, mas quando bate no bolso o patrão é obrigado a reconsiderar ${ }^{15}$.
\end{abstract}

Ao final encontramos o conteúdo da forma de reivindicação dos petroleiros em que "a única coisa que move os grandes capitalistas é o prejuízo no bolso". A espiral de hostilidade,

\footnotetext{
${ }^{14}$ Entrevista realizada pelo pesquisador em 10/02/2019

${ }^{15}$ Entrevista realizada pelo pesquisador em 10/02/2019.
} 
violência da greve tem como finalidade fazer com que o patrão sinta no bolso o prejuízo para que este reconsidere a respeito de retirar ou ampliar direitos dos trabalhadores. Assim concluímos "como" os petroleiros lutam por seus direitos.

\section{ANÁLISE CONCLUSIVA}

Numa primeira perspectiva na greve petroleira, para o trabalhador surge a necessidade de mobilização como resposta ao processo de exploração do trabalho, e no auge do processo grevista o trabalhador se dá conta de que a realidade humano-social que o circunda depende inexoravelmente da realização de seu trabalho. A paralisação do trabalho revela ao trabalhador que são seus braços, suas pernas e sua capacidade intelectiva que move a fábrica e que produz a mercadoria. A construção ideológica que o trabalhador em greve realiza traduz para sua consciência um contraste entre o mundo construído pelo seu trabalho e o mundo paralisado por seus braços cruzados. Tais realidades sociais compõem uma dualidade entre opostos que evidenciam a centralidade do trabalho na estruturação do tecido social.

Em uma segunda perspectiva a organização para a realização da greve requer um processo de aprendizagem, tentativa e erro, avanços e recuos que é orientado por graus maiores ou menores de reflexão a respeito da realidade social circundante. Um trabalhador petroleiro que passa por um, dois, três, processos grevistas acumula conhecimento a respeito do modo apropriado para impor ao patrão a garantia de avanços nas condições de trabalho. Nessa perspectiva o acúmulo de conhecimento traduz-se na organização sindical, na capacidade de realização de piquets, mobilizações, marchas, na capacidade de analisar a quantidade de dias necessários para o prosseguimento da greve e de analisar o momento mais acertado para parar. Assim, a greve configura-se não como um único ato, mas como uma processualidade de atos. Tal processualidade é assimilada conscientemente pelos trabalhadores, bem como é tornada instrumento para garantia de avanços nas condições de trabalho.

Numa terceira perspectiva, é necessário apontar a relação existente entre a direção sindical e os inúmeros trabalhadores petroleiros em greve. O impulso grevista se dissemina como um emaranhado de vontades heterogêneas e razões subjetivas dispares que se 
homogenizam numa ordem coletiva em torno de uma pauta ou conjunto de pautas entrelaçadas com as necessidades dos trabalhadores.

A direção sindical, ao propor a conflagração de uma greve, não afirma de maneira mecanicista o pôr de um fim, ao reverso: o emaranhado de vontades dos trabalhadores petroleiros é prioritário em relação a vontade da cúpula dirigente. Se assim não fosse a direção poderia convocar greves como se pressionasse uma alavanca que tivesse efeitos imediatos para a conflagração do movimento grevista. Dizer isso não significa dizer que a direção sindical não cumpre papel relevante na conflagração do papel, e nem que a direção reage como peso inerte influenciado pela massa de trabalhadores. A questão, por fim, é a de que a conflagração de uma greve pode ser originada pela vontade da direção, mas só terá êxito teleológico se houver reflexo por parte dos trabalhadores. Ou, por outro lado, a própria vontade da direção pode ser dissolvida no emaranhado de vontades conformador da massa de trabalhadores: uma greve geral convocada por um corpo de dirigentes pode se alastrar pelo tecido social e setores da classe trabalhadora impulsionarem-se à greve independentemente do chamado originário.

Por último, e o mais importante, a greve tem como finalidade, como pôr teleológico, a paralisação da produção. Nesse sentido, querer parar a produção, depende inexoravelmente com o saber como a produção se desenvolve. Ferreira e Iguti discutem a questão do saber petroleiro partindo do relato de um entrevistado por elas em que o mesmo expõe: "No primeiro dia em que fui trabalhar na Petrobrás, [o operador chefe] falou pra mim: 'Ô garoto! tem que aprender essa pipoca toda e defender a Petrobrás"” (FERREIRA e IGUTI, p. 107). É interessante notar que "entende como funciona" e "defender a Petrobrás" aparece entrelaçado. Um trabalhador petroleiro então tem que realizar o espelhamento do funcionamento da planta produtiva para opor a esse funcionamento um pôr teleológico que tenha por fim paralisar a produção. Assim, para fazer com o que, por exemplo, uma refinaria paralise é necessário compreender o funcionamento da refinaria. Compreender como funciona serve à proteção da Petrobrás.

\section{REFERÊNCIAS}

CALDEIRA BRANT, Vinicius. Paulínia: Petróleo e Política. São Paulo: CEBRAP, 1990. 
FERREIRA, Leda Leal; IGUTI, Aparecida Mari. O trabalho dos petroleiros: perigoso, complexo, contínuo e coletivo. São Paulo: Scritta,1996.

KOSIK, Karel. Dialética do Concreto. São Paulo: Paz e Terra, 2002.

LUKÁCS, Györg. Para uma ontologia do ser social, 2. São Paulo: Boitempo, 2013.

LUKÁCS, Györg. Prolegômenos para uma ontologia do ser social: questões de princípio para uma ontologia hoje tornada possível. São Paulo, 2010.

MÉSZÁROS, István. O poder da ideologia. São Paulo: Boitempo.

OLIVEIRA, Francisco de. O elo perdido: classe e identidade de classe. São Paulo: Brasiliense, 1987.

OLIVEIRA JR., Franklin. A usina dos sonhos: nascimento, ascensão e refluxo da organização sindical dos trabalhadores da indústria da destilação e refinação do petróleo no Estado da Bahia: 1954-1964, Salvador: UFBA, 1995.

SCOTT, James C. A dominação e a arte da resistência: discursos ocultos. Lisboa: Letra Livre, 2013.

THOMPSON, Edward P. A formação da classe operária inglesa. Rio de Janeiro: Paz e Terra, 1987.

SADER, Eder. Quando novos personagens entraram em cena: experiências, falas e lutas dos trabalhadores da Grande São Paulo, 1970-80. Rio de Janeiro: Paz e Terra, 1988.

Submetido em: 10/03/2021

Aprovado em: 11/04/2021 